\title{
Enhancing Studies of Pharmacodynamic Mechanisms via Measurements of Metabolic Flux: Fundamental Concepts and Guiding Principles for Using Stable Isotope Tracers
}

\author{
Natalie A. Daurio, Sheng-Ping Wang, Ying Chen, Haihong Zhou, David G. McLaren, \\ Thomas P. Roddy, Douglas G. Johns, Denise Milot, Takhar Kasumov, Mark D. Erion, \\ David E. Kelley, and Stephen F. Previs \\ Merck \& Company, Inc., Kenilworth, New Jersey (N.A.D., S.P.W., Y.C., H.Z., D.G.M., T.P.R., D.G.J., D.M.E., D.E.K., S.P.F.), and \\ Department of Pharmaceutical Sciences, College of Pharmacy, Northeast Ohio Medical University, Rootstown, Ohio (T.K.)
}

Received March 11, 2017; accepted June 14, 2017

\begin{abstract}
Drug discovery and development efforts are largely based around a common expectation, namely, that direct or indirect action on a cellular process (e.g., statin-mediated enzyme inhibition or insulin-stimulated receptor activation) will have a beneficial impact on physiologic homeostasis. To expand on this, one could argue that virtually all pharmacologic interventions attempt to influence the flow of "traffic" in a biochemical network, irrespective of disease or modality. Since stable isotope tracer kinetic methods provide a measure of traffic flow (i.e., metabolic flux), their inclusion in study designs can yield novel information regarding pathway biology; the application of such methods requires the integration of knowledge in physiology, analytical chemistry, and
\end{abstract}

mathematical modeling. Herein, we review the fundamental concepts that surround the use of tracer kinetics, define basic terms, and outline guiding principles via theoretical and experimental problems. Specifically, one needs to 1) recognize the types of biochemical events that change isotopic enrichments, 2) appreciate the distinction between fractional turnover and flux rate, and 3) be aware of the subtle differences between tracer kinetics and pharmacokinetics. We hope investigators can use the framework presented here to develop applications that address their specific questions surrounding biochemical flux, and thereby gain insight into the pathophysiology of disease states, and examine pharmacodynamic mechanisms.

\section{Why Are Measurements of Metabolic Flux Important in Drug Discovery?}

Many of the most challenging diseases are associated with metabolic dysregulation. Although genomic and proteomic analyses can suggest drug targets by contrasting healthy and disease states (Plenge et al., 2013), these analyses describe isolated events and do not account for the translation of altered expression profiles into aberrant metabolic activities. Since biochemical pathways are controlled by compensatory and often redundant regulatory mechanisms, including feedback loops that maintain necessary functions under various insults, it is not surprising to encounter disconnects between expression profiles and biochemical flux. For example, although $\mathrm{Ob} / \mathrm{Ob}$ mice have a downregulated expression of lipogenic genes in adipose tissue, tracer-based studies demonstrate increased triglyceride synthesis and de novo lipogenesis (Turner et al.,

https://doi.org/10.1124/jpet.117.241091.
2007). In other cases, one can observe changes in expression profiles that reflect the directional change of a metabolic flux; however, the magnitude of change that is observed at a given step in a pathway can lead to confusion when considering which reaction to target (Kasturi et al., 2007). Although intuition might suggest that one should target genes and proteins that display the largest change in expression profile, sensitivity assessments suggest targeting expression signatures with the smallest change (Fell, 1997).

In contrast to the snapshots that are captured by expression or concentration profiles, isotope tracers allow one to quantify pathway flux, synthesis rate, and half-life. For example, simvastatin does not immediately change the amount of cholesterol in isolated hepatocytes; however, flux measurements demonstrate an unambiguous effect on pathway biology. Note the decrease in cholesterol synthesis (Fig. 1). Similarly, the addition of fructose does not immediately alter cholesterol concentration; however, tracer data demonstrate an increase in cholesterol synthesis, which is inhibited by simvastatin (Fig. 1). Since metabolic flux can change

ABBREVIATIONS: AUC, area under the curve; CSF, cerebrospinal fluid; FCR, fractional clearance rate; FSR, fractional synthesis rate. 


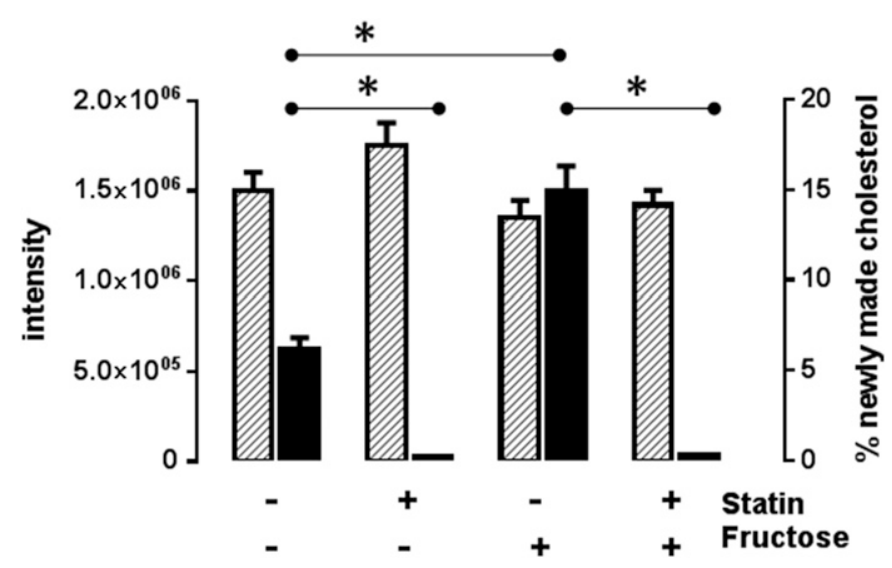

Fig. 1. Contrasting static and kinetic assessments of cholesterol homeostasis. Primary human hepatocytes were incubated in the presence of $10 \mathrm{mM}$ glucose and $10 \%\left[{ }^{2} \mathrm{H}\right]$ water for 36 hours. Standard media were supplemented with an additional $10 \mathrm{mM}$ fructose and/or $1 \mu \mathrm{M}$ simvastatin for the entire incubation period. Cholesterol content and $\left[{ }^{2} \mathrm{H}\right]$ labeling were determined using gas chromatography-mass spectrometry after saponification, extraction, and acetylation (Jensen et al., 2012). The relative signal intensity (a surrogate of total content, shaded bars) is comparable in all conditions, but there were marked differences in the contribution of newly made cholesterol (solid bars, $* P<0.01, n=6$ wells per condition; data shown as mean \pm S.E.M.).

independent of changes in an expression profile (Turner et al., 2007) and since a flux rate must change before we can expect a concentration to change (Harding et al., 2015), the ability to measure metabolic flux should enhance pharmacodynamic studies.

Because a lack of efficacy in patients remains a key reason why drug candidates fail (Arrowsmith and Miller, 2013; Plenge et al., 2013; Cook et al., 2014), it seems important to cross-reference a parts list (i.e., an expression profile) with an instruction manual (i.e., an integrative study of organ physiology and/or pathway biology). Presumably, we all agree that roadmaps can help us find our way across a city; however, digital applications, which also report the traffic flow, are of the greatest utility. Since stable isotope tracer methods yield a measure of traffic flow and are well validated and safe for use in in vitro and in vivo systems (including humans), their application should enhance translational studies and yield mechanistic information through all phases of development (Turner and Hellerstein, 2005). In fact, many reports describe tracer methods being used to gain new knowledge into pathophysiological changes in disease states and to support drug discovery (http://www.clinicaltrials.gov). Likewise, there are published examples of tracers informing on a pharmacodynamic mechanism of action (Cuchel et al., 1997; Hundal et al., 2000; Petersen et al., 2000; Cascante et al., 2002; Stiede et al., 2017; Reyes-Soffer et al., 2017), including fundamental studies that aim to explain the pathophysiology of disease states (Cline et al., 1999; Donnelly et al., 2005; Sunny et al., 2011; Decaris et al., 2015, 2017).

Although the ability to design and conduct tracer studies requires a general working knowledge of physiology, analytical chemistry, and mathematical modeling (Wolfe and Chinkes, 2005; Waterlow, 2006), the general principles have been outlined in a number of excellent references (London, 1949; Solomon, 1949; Reiner, 1953a,b; Roberrtson, 1957; Zilversmit, 1960; Zierler, 1961; Heath and Barton, 1973); unfortunately, there are discrepancies regarding "right" or "wrong" approaches (Katz, 1992; Landau and Wahren, 1992; Landau et al., 1998; Edland and Galasko, 2011; Previs and Kelley, 2015). Our goal here is to review the key issues that impact tracer-based studies and show that adherence to a few guidelines should help circumvent confusion regarding data interpretation and therein yield a clear understanding of pharmacodynamic mechanisms. Attention to these seemingly subtle points should allow reliable applications and expand the utility of tracer methods in drug discovery studies. Rather than restate many of the mathematical expressions that can be found in the literature (London, 1949; Solomon, 1949; Reiner, 1953a,b; Robertson, 1957; Zilversmit, 1960; Zierler, 1961; Heath and Barton, 1973), where possible, we will use everyday examples to keep this review more conversational.

\section{Basic Definitions and Principles Surrounding Tracer-Based Studies of Metabolic Flux}

A starting point centers on defining the term pool size; fundamentally, the pool size is a mass. For a circulating marker, the pool size represents the concentration multiplied by the distribution volume (e.g., $\mathrm{mg}$ analyte per $\mathrm{ml} \times$ total $\mathrm{ml}=\mathrm{mg}$ analyte). Obviously, one can measure the concentration of a circulating analyte (e.g., albumin), but it can be difficult to calculate the total mass of an analyte without knowledge of its distribution volume; for example, albumin can be found in intravascular and extravascular spaces. Studies of lipoprotein flux often assume a distribution volume that represents $\sim 4 \%-5 \%$ of body mass (Lichtenstein et al., 1990; Parhofer, et al., 1991). Although this assumption is reasonable, the volume can be ignored if it is proportional to body mass across groups; the analyte concentration then provides a marker of the relative pool size.

Second, we should differentiate between fractional turnover [i.e., fractional synthesis rate (FSR) and fractional clearance rate $(\mathrm{FCR})]$ and flux rate. FSR and FCR represent the movement of a proportion of a pool per unit of time (e.g., fraction of the analyte pool per min) whereas flux rate represents the movement of a mass per unit of time (e.g., mg of analyte per min) (Fig. 2), these terms are described and related using eq. 1 and eq. 2 :

$$
\text { fractional turnover }\left(\mathrm{min}^{-1}\right)=\text { flux rate }\left(m g \times \mathrm{min}^{-1}\right) / \operatorname{pool} \operatorname{size}(m g)
$$

flux rate $\left(m g \times \min ^{-1}\right)=$ fractional turnover $\left(\min ^{-1}\right) \times \operatorname{pool} \operatorname{size}(m g)$.

As implied from Fig. 2, the movement of molecules in a pool can be expressed in relative or absolute units (e.g., per min or $\mathrm{mg} / \mathrm{min}$, respectively). Note that flux rate is typically normalized against the body weight, tissue mass, cell number, etc.

Studies often assume a metabolic steady state; that is, the endogenous pool size is not changing over the period when a tracer is administered. However, tracer levels may change over time (and may therefore be in an isotopic nonsteady state). For example, if we wanted to measure the movement of glucose molecules in the plasma, we could administer $\left[\mathrm{U}^{13} \mathrm{C}_{6}\right.$ ]glucose into the circulation and then plot a time course of its labeling, we could draw conclusions regarding the kinetics by examining the fractional turnover and/or the flux rate (Shipley and Clark, 1972; van Dijk et al., 2013; 


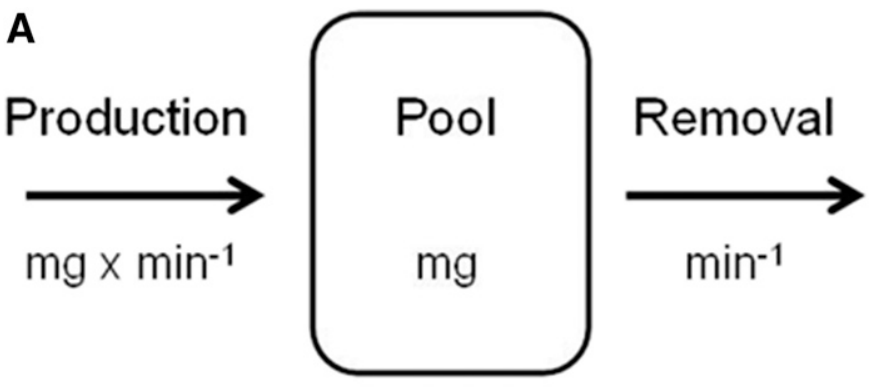

B

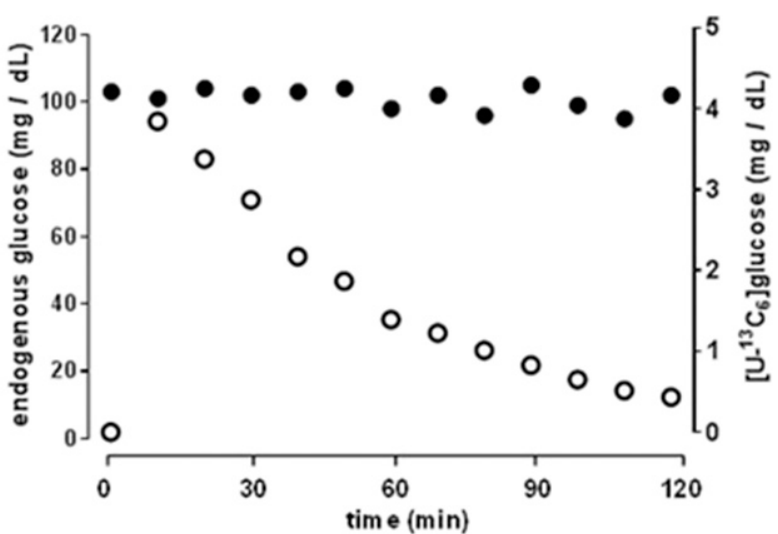

Fig. 2. Outline of metabolic flux terms and tracer logic. Three critical terms to consider are pool size, fractional turnover, and flux rate. Fractional turnover and flux rate represent measures of pathway activity, and they are related to each other through the pool size (eq. 1 and eq. 2). Different units can be used to describe production and removal of material from a pool (A). Most often, studies are run under conditions of a metabolic steady state, where the amount of some endogenous tracee is not changing with time (B); closed circles represent endogenous glucose. In those cases, the FSR equals the FCR, and the production rate equals the removal rate. Isotope tracers can be administered and measured under conditions of nonsteady state ( $\mathrm{B}$, open circles represent a bolus administration of $\left[\mathrm{U}^{13} \mathrm{C}_{6}\right.$ ]glucose. Note that 1 ) data should ideally be expressed as enrichment (i.e., labeled glucose/total glucose) and 2) we expect equal loss of labeled and endogenous glucose from the pool, and mass-balance is preserved since there is continuous production of unlabeled glucose.

Wang et al., 2016). Investigators in the field of lipoprotein kinetics often use flux rate to describe production and FCR to describe removal (Millar et al., 2015), but readers should recognize that studies are generally run under conditions of a metabolic steady state where FSR equals FCR and production rate equals removal rate.

Perhaps the following scenario may clarify the differences between fractional turnover and flux rate. Imagine a scenario where an adult is holding the hand of toddler while taking a walk. An observer could draw two different conclusions if asked to explain who is walking faster. If the observer counts the number of steps the adult and toddler takes, he or she would likely conclude that the toddler is walking faster. Readers will recognize that the toddler's little feet and shorter legs will require more steps in the same amount of time (i.e., walk faster) compared with the adult; however, the observer would also conclude that both the adult and the toddler covered the same total distance in the same amount of time (remember, they are holding hands so they start and end the walk together). Thus, one question could yield two apparent answers. Counting the number of steps per time is analogous to measuring a fractional turnover, whereas counting the total distance is analogous to measuring a flux rate; each provides a measure of activity but with very different meaning in regard to movement.

Fractional turnover is an interesting term that is discussed later in the context of inferring mechanism of action; for now, readers should recognize the links to half-life and residence time. If studies have looked at a first-order process, then the fractional turnover is related to the half-life and residence time using eq. 3 and eq. 4 :

$$
\begin{aligned}
\text { half-life } & =\ln 2 \times \text { fractional turnover }^{-1} \\
\text { residence time } & =1 \times \text { fractional turnover }^{-1} .
\end{aligned}
$$

The half-life is the amount of time required for half of the pool to be replaced; the residence time is the average amount of time a molecule stays in the pool (Berman et al., 1982). Accordingly, the time required to renew the pool is truly altered if the fractional turnover is changed, which is worth considering in the context of pharmacodynamic studies. For example, if we accept the hypothesis that oxidative stress can damage molecules within a given population, making them more likely to react with the body in a harmful way, then there is value in thinking about kinetics from the perspective of half-life and/or residence time. If a therapeutic agent could shorten the residence time of a harmful end-product, one might be better positioned in terms of potential outcomes. Consider that each household will generate a certain amount of garbage every year (i.e., the absolute flux rate is fixed). Imagine a scenario in which we remove our trash every week versus every 3 months. The increased turnover (weekly vs. quarterly garbage removal) has advantages even if we do not change the overall rate of garbage output. The concept of substrate cycling as a means of affecting metabolic control is based on the logic of having fast interconversions relative to net flux rates (Newsholme, 1978). Knowledge of half-life and/or residence time certainly provides a useful assessment of the physiologic status.

An assumption is made when tracers are used to quantify the fractional turnover and flux rate (i.e., there is no bias or discrimination between the absorption, distribution, metabolism, or elimination of a tracer and a tracee). Readers may note that enzymologists exploit isotope effects to probe transition states (Cleland, 2005); however, physiologic studies assume that there is no measurable difference between the fate of the tracer and the tracee (Wolfe and Chinkes, 2005; Waterlow, 2006); or, if there is a difference, it is equal across groups. Because of this assumption, extra consideration must be given to the events that affect isotopic "enrichment," which has special importance in pulse-chase experiments. Note that although many of the mathematical concepts used in tracer kinetics (London, 1949; Solomon, 1949; Reiner, 1953a,b; Robertson, 1957; Zilversmit, 1960; Zierler, 1961; Heath and Barton, 1973) are interchangeable with those used in pharmacokinetics (Gabrielsson and Weiner, 2000; Rowland and Tozer, 2011), there are a few key differences. For example, when a drug is administered via an infusion protocol, its concentration will increase. When the infusion is stopped, the concentration will decrease via the influence of a removal process; this is easy to visualize by plotting the concentration $(y$-axis) versus time ( $x$-axis). A distinction must be appreciated when stable isotope tracers are used: the $y$-axis almost always reflects the enrichment of an analyte (a proportion of labeledto-unlabeled molecules), which is in strong contrast to plots of drug concentration on the $y$-axis. Some readers will recognize 
that the literature surrounding stable isotope tracers contains terms including enrichment, mole fraction, and tracer-tracee ratio (Wolfe and Chinkes, 2005; Ramakrishnan, 2006), although the equations and notation can impact certain experiments (Ramakrishnan, 2006); these terms are considered equivalent for our discussion.

Since we assume that labeled and unlabeled molecules are indiscriminately metabolized, it is not possible for clearance, degradation, elimination, or removal processes to affect the enrichment or change the proportion of labeled-to-unlabeled molecules (Previs et al., 2004). Although one can cleverly derive equations that imply that degradation affects isotope labeling (Holm et al., 2013), tracer studies assume that removal processes do not change enrichment. Since our perspective contrasts to the logic that is applied in some pulse-chase studies, we discuss how an appreciation of this point can simplify experimental designs and enhance data interpretations (Bateman et al., 2006; Mawuenyega et al., 2010; Millar et al., 2015). Readers can test our assertion without any elaborate experimentation. Simply pour a cup of coffee and note the color; it will be black (this represents the endogenous "cold" tracee molecules). Adding a splash of milk (tracer) will make the color less black. This is analogous to what happens when one adds tracer to a system; the pool of endogenous molecules becomes enriched, the proportion of labeled-to-unlabeled molecules increases. When the infusion of the labeled precursor is discontinued, one will observe a decrease in the enrichment of the product (e.g., protein) molecules; this decrease is thought to reflect clearance (Bateman et al., 2006), which is not possible if labeled and unlabeled molecules undergo equal metabolism. If you sit back and take a drink, you will recognize that there is now less coffee in your cup, but you will note that the color has remained the same as it was before you started to drink. Clearance, removal, elimination, or degradation processes will reduce the concentration of a product, but they will not influence the proportion of labeled-to-unlabeled molecules, just as drinking from your cup will reduce the amount of coffee without influencing the proportion of milk to coffee. The color will only approach the original black color if one adds more coffee to a nearly empty cup, analogous to the synthesis of new unlabeled product molecules once the tracer (precursor) infusion is stopped.

The scenario that was just described draws out a distinction regarding metabolic steady state and isotopic steady state (Fig. 2). Many biologic problems are studied under conditions of a metabolic steady state; that is, the concentration of some end product is not changing over the time. We observe a metabolic steady state because production rates and removal rates are equal; however, we can also observe a change in isotopic enrichment over the same period. In the extreme setting, when we stop the influx of new molecules and allow only for the removal of existing molecules, we should observe a decrease in the amount of a target analyte, but we should not observe a change in the enrichment. Indeed, we do observe changes in enrichment during a chase period; however, this is because new "cold" molecules are produced that therein replace the loss of a mixture of "cold" and "labeled" molecules; it is this production of "cold" molecules that subsequently maintains a metabolic steady state.

A final definition concerns first-order reactions and zeroorder reactions (Fig. 3), that is, when the reaction rate varies

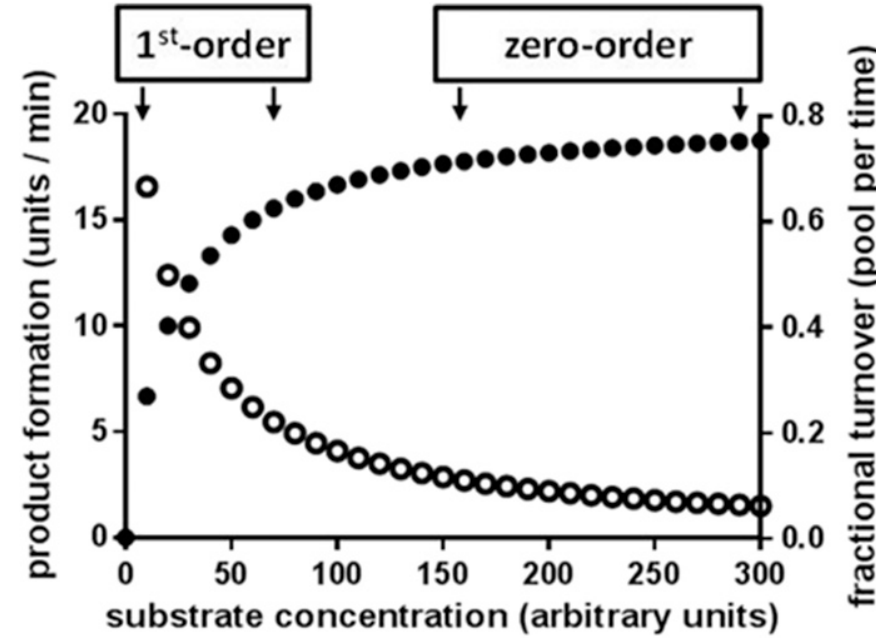

Fig. 3. Hypothetical model of reaction order in the context of an enzyme catalyzed reaction. According to the Michaelis-Menton model, the rate of product formation will reach a saturation point as the substrate concentration increases. Flux rate can be determined at each substrate concentration (solid symbols); that is, $v=\left(V_{\max } \times S\right) /\left(K_{\mathrm{m}}+S\right)$. At lower concentrations, there is a more direct relationship between the change in substrate concentration and the flux rate (e.g., first-order region). This relationship diminishes as the reaction approaches saturation (e.g., zero-order region). If we assume a constant volume, then we can calculate a fractional turnover at each substrate concentration (open symbols). Since we know the flux rate $(v$, or product formation) and the pool size (substrate concentration $\mathrm{x}$ volume), we can see that the fractional turnover (flux rate/pool size, eq. 1) also changes over the course of the experiment (e.g., the fractional turnover decreases as the flux rate increases).

with the reactant concentration and when the reaction rate is independent of the reactant concentration, respectively. According to general principles (e.g., the Michaelis-Menton model of enzyme catalyzed reactions, numerous physiologic events (including transport processes) have the potential to be first- and zero-order, depending on the substrate concentration(s) and the $K_{\mathrm{m}}$. An example of this is seen in studies of triglyceride metabolism; circulating lipid levels can span a broad range and begin to saturate the removal process(es) at high, but physiologically relevant, concentrations (Grundy et al., 1979). Mechanistic studies of lipoprotein lipase, which catalyzes the degradation of circulating triglycerides (Fielding, 1976), demonstrated that there is nearly a 10-fold difference between the $K m$ in the heart versus adipose tissue, implying that the heart will almost always be saturated with substrate ( zero-order kinetics), whereas the adipose tissue flux will respond to changes in circulating concentration ( first-order kinetics). These types of tissue-specific differences may play an important role in maintaining normal lipid homeostasis (Previs et al., 2014). A recent study concluded that most intracellular substrate concentrations exceed the $K \mathrm{~m}$, implying that metabolic flux more closely approximates zero-order kinetics (Park et al., 2016). This would imply that changes in substrate concentration will have little effect on pathway flux. A comparable cell-based study concluded that, in fact, reactions may not exceed the $K_{\mathrm{m}}$ (Wahrheit et al., 2014). Clearly, this matter of reaction order should be considered on a case-by-case basis. A discussion of higher-order reactions, which further complicate the modeling, is beyond the scope of our review. 


\section{Applying the Definitions and Concepts to a Hypothetical Metabolic Problem}

Considering the terms that we have defined, one may ask, What are the most informative ways to characterize a kinetic phenotype? For example, investigators have tried to explain differences in pool sizes by comparing FSR to FCR (Bateman et al., 2006) or by comparing production rate to FCR (Millar et al., 2015). This section considers a theoretical problem to look at whether these terms truly inform on biochemical traffic flow and allow one to draw conclusions regarding mechanisms that change pool size.

If we assume that biologic processes follow some type of saturation model (e.g., Michaelis-Menton), an interesting relationship appears regarding fractional turnover and flux rate. In fact, fractional turnover (FSR or FCR) does not reflect metabolic flux as the reaction approaches zero order (Fig. 3). For example, as the concentration increases from 150 to 300 units, the flux remains virtually constant $\left(\sim 18\right.$ and $\sim 19$ units $\times \mathrm{min}^{-1}$, respectively); however, the fractional turnover (i.e., the rate of product formation divided by the substrate concentration) substantially decreases over the same range (from 0.12 to 0.062 , respectively). This example demonstrates that as the reaction approaches saturation, wide shifts in the fractional turnover (nearly doubling here) reflect virtually no change in the flux rate ( $\sim 6 \%$ difference here): 150 units $\times 0.12$ minute $^{-1}=18$ units $\times$ min $^{-1}$ versus 300 units $\times 0.062$ minute $^{-1}=18.6$ units $\times$ min $^{-1}$

When the reaction approximates first-order kinetics (Fig. 3), we see that a change in the concentration (from 20 to 60 units) is now associated with more dramatic changes in both the flux rate and the fractional turnover (from 10 to 15 units $\times \min ^{-1}$ and from 0.50 to 0.25 , respectively). Although the magnitude of the change in fractional turnover now more closely reflects the change in flux, the directionality is opposite: a marked increase in the fractional turnover represents a sizeable decrease in the flux (i.e., 20 units $\times 0.5$ minute ${ }^{-1}=10$ units $\times \mathrm{min}^{-1}$ versus 60 units $\times 0.25$ minute $^{-1}=15$ units $\times \min ^{-1}$. According to this example, if one observes an increase in FCR, it is not possible to conclude that this reflects an increase in the removal rate. Fractional turnover certainly provides a measure of relative metabolic activity, but this should not be confused with a measure of biochemical flow.

This example demonstrates that both fractional turnover and flux rate can be used to characterize a metabolic phenotype; however, they may signify opposite effects. This topic is discussed in more detail to follow since it is of central importance in various studies and since our view appears to go against commonly applied logic (Bateman et al., 2006, 2007; Dobrowolska, et al., 2014; Elbert, et al., 2015; Millar et al., 2015). Our perspective on this topic follows comments that were made by Steele regarding the meaning of turnover constants and reaction rate constants; he also demonstrated that tracer decay curves can create an illusion of being firstorder even if the reaction is not following such a scheme (Steele, 1971). A deeper consideration of those matters is beyond the scope of this discussion.

\section{Studying Metabolic Flux In Vivo: Measurements of Water Turnover}

We now consider a simple metabolic problem to examine the concepts surrounding pool size, fractional turnover, and flux rate using an in vivo model. Water kinetics were measured in C57Bl/6J mice $(28.2 \pm 1.3 \mathrm{~g}$ mean \pm S.E.M., $n=3)$ and Sprague-Dawley rats $(348 \pm 10 \mathrm{~g}$ mean \pm S.EM, $n=3)$, animals were allowed free access to $5 \%\left[{ }^{2} \mathrm{H}\right]$ labeled drinking water for 7 days and then switched to regular drinking water for an additional 7 days. There were several reasons for contrasting water kinetics in mice versus rats. First, this protocol will generate data in which there is an exponential rise in plasma water labeling while animals are exposed to $\left[{ }^{2} \mathrm{H}\right]$ labeled drinking water and a decay of enrichment when the animals are switched to regular drinking water; that is, this is a pulse-chase experiment under conditions of a metabolic steady state (Bateman et al., 2006). Second, we could draw out concepts about different pool sizes and link points regarding fractional turnover and flux rate. We could experimentally determine whether comparing FSR with FCR or production rate with FCR would yield insight regarding the differences in pool size. Finally, we could cross-validate tracer estimates of water kinetics with an orthogonal (nontracer based) approach, that is, measure the change in weight of the water bottles over 24-hour intervals; since some spillage can occur, this approach may slightly overestimate the true water turnover but still will provide a reasonable surrogate assessment. These studies were approved by our Institutional Animal Care and Use Committee.

As expected, the water intake (determined by weighing the bottles) was different between mice and rats: $6.1 \pm 0.5$ and $26.2 \pm 1.6 \mathrm{ml} / 24$-hour period, respectively (mean \pm S.E.M., Fig. 4). Since rodents obtain $\sim 60 \%-70 \%$ of their water by drinking, with the remainder coming from digestion and respiration (Lee et al., 1994), the total water flux is $\sim 9$ and $\sim 40 \mathrm{ml}$ per day in mice and rats, respectively. Since these are lean animals, fed a standard low-fat rodent chow, the total body water pool (i.e., body weight $\times 0.70$ ) is $\sim 20$ and $\sim 244 \mathrm{ml}$ in mice and rats, respectively. Therefore, the fractional turnover is $\sim 9 / 20$, or 0.45 , and $\sim 40 / 244$, or 0.16 , pools of water per day in mice and rats, respectively.

The $\left[{ }^{2} \mathrm{H}\right]$ labeling of plasma water followed the expected trends for a pulse-chase experiment (Fig. 4); the ascending and descending enrichments were fit to single exponentials for individual animals using GraphPad Prism (GraphPad Software, San Diego, CA). Since the animals are in a metabolic steady state, one expects agreement between the increase and the decrease in enrichment values (assigned to the terms FSR and $F C R$, respectively); furthermore, since body weight was stable, the water pool was therefore not changing with time and the input and output rates of water flux are equal. Compared with rats, mice display a greater fractional turnover; however, the water flux (eq. 2) was reduced in mice versus rats (Fig. 5). The overall data set demonstrates that tracer-based estimates of fractional turnover and absolute flux rate agree with direct measurements of water consumption.

Can we use these kinetic data to explain why the pool sizes are different? Although the decrease in water labeling (what some might call the FCR) is $\sim 3$ times lower in rats than in mice (Fig. 5B), the water flux is actually $\sim 4$ times greater in rats versus mice (Fig. 5C). Therefore, fractional turnover does not really provide a useful index of mass balance. Knowing that the FCR is lower in rats cannot explain the existence of a greater pool size of body water; water pool size and turnover are in a metabolic steady state and not changing over the course of the study. This example demonstrates that 
A

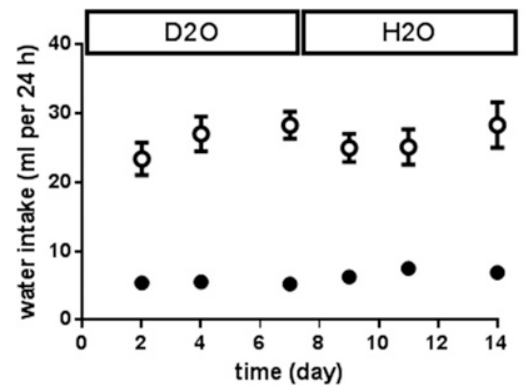

B

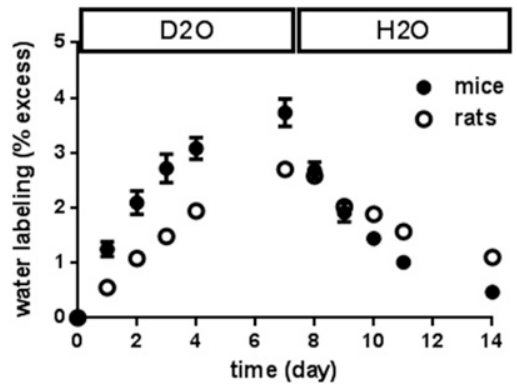

Fig. 4. Water dynamics in rodents. The change in weight of the water bottles was determined over 24-hour intervals in mice (solid circles) and rats (open circles). Water intake was not affected during the period when animals were given $\left[{ }^{2} \mathrm{H}\right]$ water versus regular tap water, but there was a difference between mice and rats (A); $P<0.01$ using a two-way $t$ test and assuming equal variance). The $\left[{ }^{2} \mathrm{H}\right]-$ labeling of plasma water (Shah et al., 2010) increased over time when animals were given $\left[{ }^{2} \mathrm{H}\right]$ water, and there was an expected decrease in $\left[{ }^{2} \mathrm{H}\right]$ labeling when animals were switched to regular tap water (B). Data are shown as mean \pm S.E.M., $n=3$ per group per time point. knowledge of absolute flux inputs (i.e., water intake and production) and fractional turnover cannot allow one to make statements regarding why pool sizes are different or whether the pool size will change over time (Bateman et al., 2006, 2007; Dobrowolska et al., 2014; Elbert et al., 2015; Millar et al., 2015). Stated another way, if we are told that 20 people enter a restaurant every hour and that $5 \%$ of the total people who are there leave over the same interval, could we determine if the number of people inside the establishment were increasing, decreasing, or remaining constant? We could make statements only regarding a change in the number of people inside the restaurant if we knew how many people were inside at the start or if we compared the number of people entering with the number of people leaving.

\section{Using Tracer Studies to Make a Sound Interpretation of Physiologic Regulation}

To this point we have defined critical terms (Fig. 2) and outlined their application in the context of theoretical (Fig. 3) and in vivo studies (Figs. 4 and 5). We hope readers are becoming familiar with high-level concepts that are used in tracer studies, and there are now two issues that should be considered. First, how does one approach experimental designs to determine biochemical flux? Second, how can one ensure some confidence regarding the data interpretation? We consider these questions by reviewing technical details that affect investigational plans.

\section{How Can We Measure FSR and FCR?}

If studies are conducted under a metabolic steady state, one can infer the fractional turnover by injecting a tracer into a pool and then measuring its dilution over time (Wolfe and Chinkes, 2005; Waterlow, 2006). This approach works reasonably well in cases where one is interested in the kinetics of small molecules (e.g., glucose, Fig. 2) (van Dijk et al., 2013; Wang et al., 2016); however, it is more complicated when macromolecules are considered (e.g., it is not practical to quantify proteome dynamics via the administration of a mixture of prelabeled proteins).

To determine the kinetics of larger molecules one typically follows the movement of a labeled precursor. For example, pulse-chase methods have been proposed for quantifying the FSR and FCR of a protein (Bateman et al., 2006). Briefly, the FSR is estimated during the infusion of $\left[{ }^{13} \mathrm{C}\right]$ leucine via its incorporation into a protein of interest (i.e., pulse), and the FCR is estimated when the tracer infusion is terminated via the decrease in $\left[{ }^{13} \mathrm{C}\right]$ labeling of the respective protein(s) (i.e., chase). This approach suggests that healthy and disease subjects have comparable FSRs but that a decreased FCR contributes to the accumulation of amyloid protein in human neurodegeneration (Mawuenyega et al., 2010). When this logic was applied in a recent drug development study, the data suggested that the drug-delivery vehicle induced a favorable imbalance in amyloid homeostasis; the FCR was nearly twice the FSR (Fig. 2 in Dobrowolska et al., 2014). The implications of these observations are profound. If the pulse-chase method is correct (Bateman, et al., 2006), one could consider the vehicle as a viable drug candidate (Dobrowolska et al., 2014). It was suggested that the conclusions may need to be reexamined in the context of a new mathematical model (Dobrowolska et al., 2014; Elbert et al., 2015). Although we recognize the need for rigor when modeling the pathways, especially in cases where there are inaccessible pools [e.g., cerebrospinal fluid (CSF) serving as a surrogate for brain], it is possible that there are
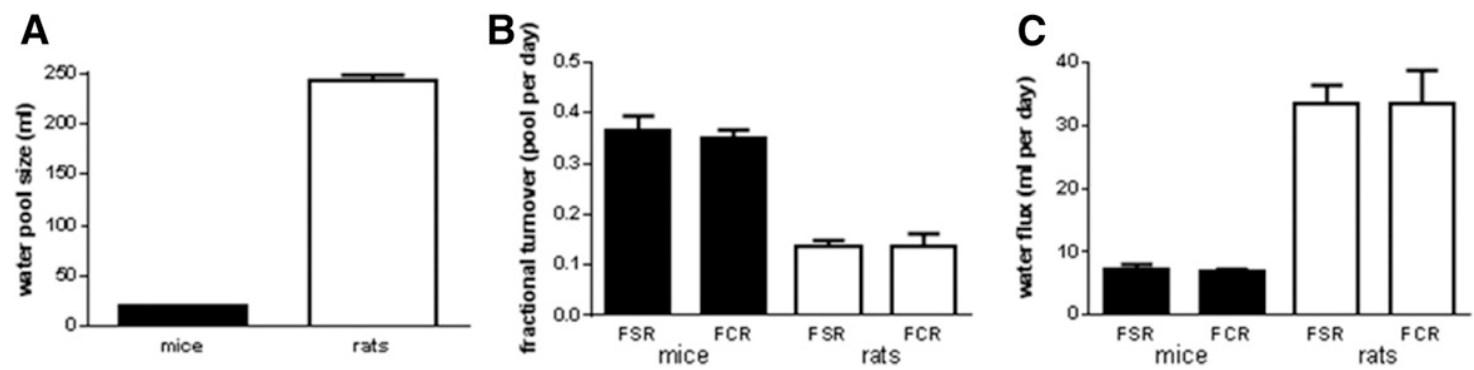

Fig. 5. Tracer-based estimates of fractional turnover and flux rate of water. The size of the water pool was calculated by assuming that $70 \%$ of body weight is lean mass (A). The enrichment data shown in Fig. 4 were fit to single exponentials to determine the fractional turnover. The FSR was estimated from the ascending plots and the FCR was estimated from the descending plots (B). The water flux rate (C) equals the product of the pool size (A) and the fractional turnover (B). There are no differences between the FSR and FCR data for a given group (paired $t$ test), but clear differences were seen between pool size (A), fractional turnover (B), and flux rates (C) between mice and rats in all cases $(P<0.01)$. Data are shown as mean \pm S.E.M., $n=3$ per group. 
misunderstandings of the principles surrounding pulse-chase protocols. This would not impact on the true efficacy of the drug, but it would raise questions regarding our understanding of the pathophysiology in the disease state (Mawuenyega et al., 2010) and limit our ability to examine the mechanism of drug action (Dobrowolska et al., 2014). Considering this scenario, we thought that an explanation of the logic surrounding the measurements might be helpful.

Quantifying the FSR. The FSR can be estimated by infusing a labeled precursor and then measuring its incorporation into a product, for example, $\left[{ }^{13} \mathrm{C}\right]$ leucine $\rightarrow\left[{ }^{13} \mathrm{C}\right]$ amyloid protein; however, there are caveats to consider. In short term protocols, one can measure the pseudolinear change in product labeling versus time and compare that with the precursor labeling using eq. 5 (Foster et al., 1993):

$$
\begin{aligned}
F S R= & (\text { change in protein labeling } / \text { change in time }) \\
& \times / \text { precursor labeling. }
\end{aligned}
$$

The precursor labeling can be 1) plasma or compartment (e.g., CSF) $\left[{ }^{13} \mathrm{C}\right]$ leucine, 2) plasma or compartment $\left[{ }^{13} \mathrm{C}\right]$ ketoisocaproate, or 3 ) the $\left[{ }^{13} \mathrm{C}\right]$ leucine labeling in some rapidly turning over protein that is made in the same cells as the target protein of interest (Waterlow, 2006). If we consider 1, 2, and 3 , there are five variants of eq. 5 . Since one can observe sizeable differences between the $\left[{ }^{13} \mathrm{C}\right]$ leucine labeling in plasma and CSF, this matter was carefully considered during the development of the protocol used in the amyloid studies, it was concluded that plasma $\left[{ }^{13} \mathrm{C}\right]$ leucine represents the precursor labeling in eq. 5 for studies of amyloid kinetics (Bateman et al., 2006; Cook et al., 2010). Studies of apolipoprotein kinetics have also demonstrated that the labeling of plasma amino acids is considerably greater than that of intracellular amino acids (Lichtenstein et al., 1990); however, those investigators typically avoid making the claim that the labeling of a plasma amino acid reflects the precursor labeling. They rely instead on a surrogate measure of intracellular amino acid labeling as a proxy for the precursor labeling. A main takehome message is that one can obtain different estimates of FSR depending on what analyte is used to represent the precursor labeling; some experimentation may be required to build confidence in one's choice (Zhou et al., 2015).

In longer-term studies and/or in cases where a protein turns over more rapidly, one can estimate the FSR from the temporal change in labeling as the protein approaches its asymptotic enrichment using eq. 6 (Foster et al., 1993):

protein labeling $_{\text {time } z}=$ protein labeling asymptotic enrichment $\cdot\left(1-e^{- \text {FSR time } z}\right)$.

Assuming that samples are collected at appropriate times, for example, more rapidly turning over proteins will require earlier sampling, and assuming that there are no errors in the data acquisition, then eq. 5 and eq. 6 will yield the same values. Since eq. 6 circumvents the need to consider a value for the precursor labeling the analyses are somewhat simplified, investigators estimate the time it takes for the protein to reach steady-state labeling (Foster et al., 1993). However, the primary assumption surrounding eq. 6 is that the precursor labeling remains stable over time (note that adjustments can be made to correct for changes in precursor labeling (Bederman et al., 2006; Ramakrishnan, 2006). In summary, there are at least six approaches for estimating the FSR during the infusion of the labeled precursor (i.e., five variants of eq. 5 and eq. 6). Each approach has assumptions, and therefore potential limitations, which should be recognized when choosing how to estimate the FSR.

Quantifying the FCR. The term FCR often refers to the latter part of a pulse-chase protocol, when the infusion of the precursor (e.g., $\left[{ }^{13} \mathrm{C}\right]$ leucine) has been terminated and one measures the decrease in product labeling (e.g., $\left[{ }^{13} \mathrm{C}\right]$ amyloid) (Bateman et al., 2006). Since tracer studies assume indiscriminate metabolism of tracer and tracee, it is not possible for clearance, removal, elimination, or degradation processes to affect the labeling, just as drinking coffee after we add a splash of milk will not reverse the color of the mixture in our cup. In fact, we can estimate the FSR during the "washout" phase (Previs et al., 2004). Therefore, in addition to the six approaches for estimating FSR (noted earlier), a seventh approach for assessing FSR involves measuring the decrease in enrichment during a "chase" (Previs et al., 2004). One should recognize, however, a caveat regarding tracer recycling (Waterlow, 2006). For example, during the tracer infusion period, the labeled amino acid precursor will be incorporated into many proteins. When the precursor infusion is terminated, labeled amino acids will be released as labeled proteins are degraded, and those labeled amino acids can be reincorporated into newly synthesized proteins (Muramatsu et al., 1963; Poole, 1971). Tracer recycling can lead to a slower dilution of label from a protein of interest; that is, a slower decrease in protein labeling can be observed during the washout phase (compared with the increase in protein labeling that occurs during the infusion period). In cases where tracer recycling occurs, the chase phase will yield little insight into the true fractional turnover of a protein; the decrease in enrichment that is observed during the "chase" (FCR) can appear to be slower than the increase that is observed during the "pulse" (FSR) because of recycling (Mawuenyega et al., 2010).

We recognize that intuition may lead one to doubt these comments, so we remind readers of examples where tracer dilution is used, in combination with arteriovenous catheterization, to estimate organ balance (Mittendorfer et al., 1998; Ekberg et al., 1999. For example, a decrease in enrichment that is observed as the tracer moves from the arterial circulation across the organ (with subsequent sampling of the venous circulation) represents the production of cold molecules. We could use another example surrounding standard isotope dilution assays. Suppose we had a test tube that contained a certain amount of plasma to which we spiked in a labeled standard, for example, $\left[{ }^{13} \mathrm{C}\right] l$ leucine. If we mix the contents of the stock tube and then make numerous smaller aliquots we will eventually deplete the main stock tube, and yet every aliquot will contain the exact same isotopic enrichment as the initial stock. Clearly, removal of material from the primary stock tube does not change its enrichment.

Two questions should now be addressed regarding FCR. First, can tracers yield a value for FCR? Yes, this is possible. Studies that use radiolabeled tracers offer some advantages since one can plot the radioactive counts (independent of the endogenous "cold" tracee) on the $y$-axis and therein estimate FCR. Because stable isotope protocols almost exclusively plot a measure of enrichment (Bateman et al., 2006; Cook et al., 2010; Mawuenyega et al., 2010 ), one should convert the $y$-axis to a tracer mass.

This brings us to our second question regarding FCR, which we should rephrase as, Does knowledge of the fractional 
turnover offer any advantage over knowledge of the flux rate? Some may be thinking that if a study examines a system under in a metabolic steady state, where FSR equals FCR (Parhofer et al., 1991), it may seem pointless to consider this matter further; however, we believe there is merit in expressing, or contrasting, fractional turnover against flux rate; readers should refer to eq. 3 and 4, where fractional turnover is linked to half-life and/or residence time; this matter is further considered in the next section. We believe the term fractional turnover is overused and that investigators should consider the use of half-life or residence time. Although experienced investigators know that this statement is more about semantics, it may be helpful to those who are new to the field.

\section{Using Tracers to Predict or Explain Changes in Pool Size: Learning about Mechanism of Action}

If our goal is to predict whether a pool size is changing, it can be misleading to compare the FSR with the FCR (Bateman, et al., 2006; Mawuenyega, et al., 2010; Dobrowolska, et al., 2014), especially as the reactions approach saturation and/or in cases of a metabolic steady-state. Likewise, it can be challenging to accurately estimate these endpoints given the assumptions regarding the measurements; however, can we gain insight regarding a mechanism of action by comparing the production rate with the FCR (Millar et al., 2015)? For example, studies may randomize disease subjects to a placebo or a treatment group, and the treatment may then modulate the concentration of an endpoint (e.g., lower apoB lipoprotein). At some point after initiating the randomization and treatment, an investigator may run a metabolic flux study in an attempt to explain the change in concentration of the endpoint between groups (e.g., tracers are administered during period 3, Fig. 6). Typically, conclusions are made in which input is described using an absolute value (production rate, e.g., $\mu \mathrm{mol} \times \mathrm{kg}^{-1} \times \mathrm{h}^{-1}$ ), and removal is described using a relative value (FCR, e.g., pool $\times \mathrm{h}^{-1}$ ); the expectation is that one can explain how the treatment changed the endpoint (Millar et al., 2015).

A few matters need to be considered regarding this scenario. Once a metabolic steady state is reached (e.g., Fig. 6, period 1 or 3 ), the FSR equals the FCR and the production rate equals the removal rate. We can appreciate that one can find apparent differences in pathway activity between groups if inputs and outputs are expressed using different units; however, this can result from the dependency of the terms (eq. 1 and 2) and the fact that a pool size has changed; for example, if the production rate is the same across two groups, but pool sizes are different, we are somewhat obligated to observe a change in FCR because the terms are all linked. Hopefully readers can agree that comparing pathway activities that are expressed in different units (absolute flux compared with a fractional turnover) is confusing and potentially misleading in terms of explaining a mechanism.

Suppose you monitored your bank account monthly. If you knew you had a certain amount of savings one month and then the next month your savings was decreased by half you might be concerned; however, you immediately realize that although you could monitor all transactions going forward, that would never explain why your savings decreased in the previous month. To determine why your balance changed would require that you examine those transactions that occurred during the period when the balance actually changes (e.g., Fig. 6, period 2).

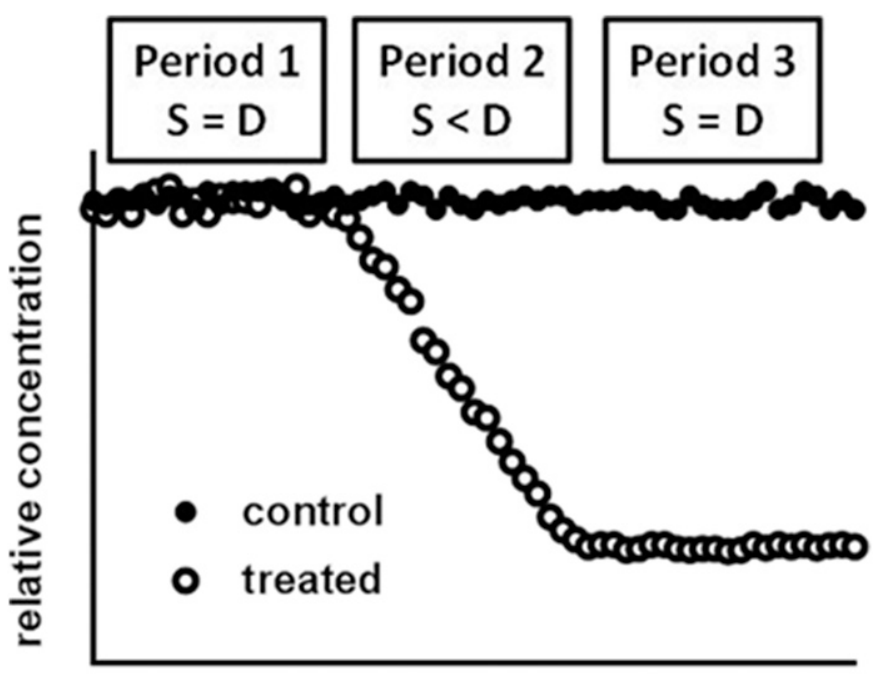

\section{relative time}

Fig. 6. Product pool dynamics. Stable concentrations of a given product reflect a condition where synthesis $(S)$ and degradation $(D)$ are equal (periods 1 and 3); that is, the system is in a metabolic steady state. During conditions where there is a change in steady-state concentration, there will be an imbalance between $S$ and $D$ (e.g., S must be less than $D$ when the concentration decreases (period 2). When a new metabolic steady state is reached, $S$ and $D$ are again equal (period 3).

Readers may be left wondering if we can explain a mechanism of action when we observe different concentrations of a given endpoint between two groups. We hope there is some general agreement that studies run under a metabolic steady state cannot explain how the system arrives at a new set point (e.g., Fig. 6, period 3) (Millar et al., 2015). Nevertheless, there is value in probing for kinetic differences between steady-state systems.

Perhaps readers may now begin to appreciate the merits of studies that examine nonsteady-state conditions where pool size changes over the period when tracers are administered (e.g., add tracers during period 2, Fig. 6). For example, if we measure the change in pool size over time and determine the synthesis rate, then we can calculate the degradation rate (Fig. 6, period 2) (Ratheiser, et al., 1999; Bederman et al., 2003, 2006, 2009). Although those designs are not practical in many instances, the synthesis rate reflects the degradation rate for a given group if and when the pool size is stable, even if different pool sizes are observed between groups (Fig. 6, period 3; and Figs. 3 and 4). Likewise, investigators can consider the use of perturbation tests that acutely move systems from a metabolic steady state (Ratheiser et al., 1999; Chavez-Jauregui et al., 2010; Vaitheesvaran et al., 2010; McLaren, et al., 2016). Those approaches can unmask hidden phenotypes and address questions regarding metabolic flexibility and physiologic response capacity. Whereas a fractional turnover, measured in a metabolic steady state, may suggest an altered half-life, acute stressors (e.g., a meal tolerance test) might allow one to examine relative $V_{\max }$ and $K_{\mathrm{m}}$-type parameters and thereby suggest biochemical events that might be contributing to the phenotype.

\section{Relating Tracer Dose, Area under the Curve, and Metabolic Activity: Quantifying the Conversion of a Precursor to a Product}

Our final discussion centers on the relation between area under the curve (AUC) and a metabolic activity. Although this 
concept is immediately obvious in pharmacokinetic modeling (i.e., clearance $=$ dose of drug/AUC), it has limited meaning in tracer studies unless one accounts for isotope dilutions and exchanges (Jin et al., 2013; McLaren et al., 2013). Just as knowledge of bioavailability and distribution is needed for AUC to accurately reflect the metabolic rate surrounding drug clearance (Gabrielsson and Weiner, 2000; Rowland and Tozer, 2011), similar caveats apply when tracers are used to infer metabolic activity. For example, we might give a known dose of a labeled precursor to control and drug-treated subjects and then observe differences in the movement of the tracer from a precursor pool to a product pool (e.g., the conversion of $\left[{ }^{2} \mathrm{H}_{5}\right]$ glycerol $\rightarrow\left[{ }^{2} \mathrm{H}_{5}\right]$ triglyceride or $\left[{ }^{13} \mathrm{C}_{3}\right]$ lactate $\rightarrow\left[{ }^{13} \mathrm{C}\right]$ glucose is reduced in drug-treated versus control subjects). To draw meaningful conclusions regarding pathway activity, we must account for the fact that the isotope labeling could 1) be "scrambled" as it undergoes conversion to the product and/or 2) experience differential dilution caused by changes in the halflife and/or the amount of endogenous tracee observed in the groups (Jin et al., 2013; McLaren et al., 2013).

Figure 7 outlines examples of dilution effects. The metabolic scheme (Fig. 7A) shows that a precursor can either be irreversibly lost or converted to a product; the precursor can also mix with a side compartment that "scrambles" the isotopic distribution pattern (see Fig. 3 in Previs et al., 2014). Figure 7 demonstrates the temporal change in product labeling if the same amount of tracer is given to two subjects as a single bolus, and the only difference between the subjects is the conversion of precursor $\rightarrow$ product (i.e., the difference in product labeling in Fig. 7B reflects a difference in the parameter $k_{2}$; we expect a $50 \%$ reduction in one versus another). Fig. 7, C and D, also demonstrate differences between the product labeling despite the fact that $k_{2}$ is the same in the respective subjects; these data reflect changes in the precursor system and have nothing to do with the conversion of precursor $\rightarrow$ product; Fig. 7C demonstrates what happens if the precursor pool size is increased by a factor of 2 , whereas Fig. $7 \mathrm{D}$ demonstrates what happens if the half-life of the precursor is reduced by a factor of 2. It is necessary to recognize the impact of these events if tracers are used to study pharmacodynamics and/or quantify target engagement activity (Landry et al., 2011).

Figure 8 expands on the problem by demonstrating the effect of isotopic scrambling. Note that although we administered $\left[\mathrm{U}^{13} \mathrm{C}_{3}\right.$ ]lactate $(\mathrm{M}+3)$, the dominant glucose species is $\mathrm{M}+2$,
A

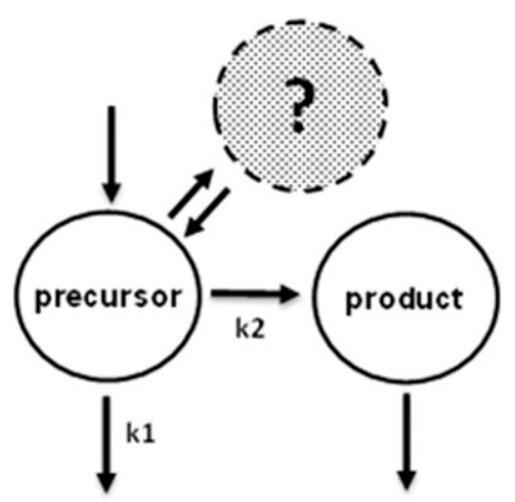

C

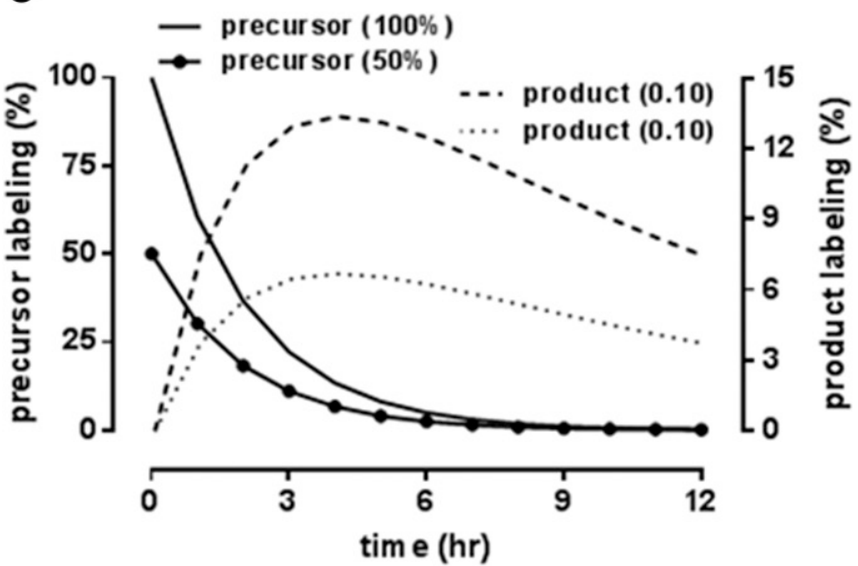

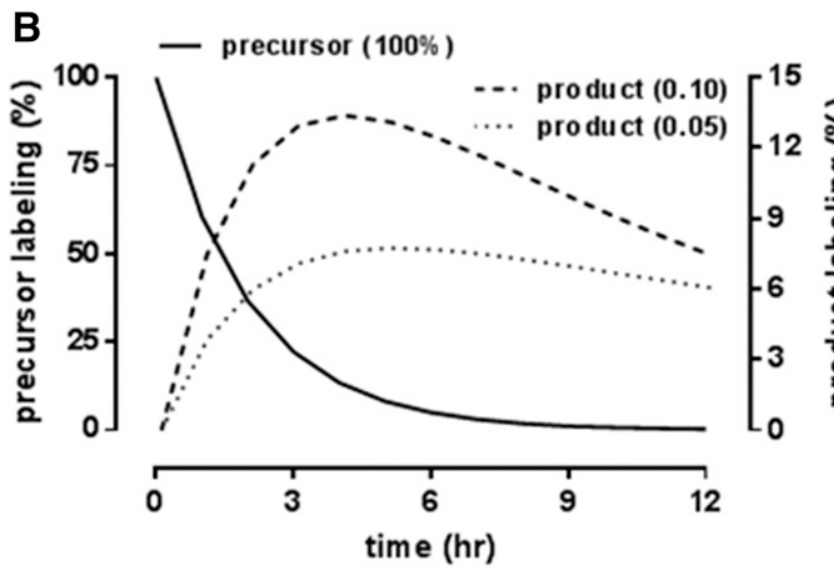

D

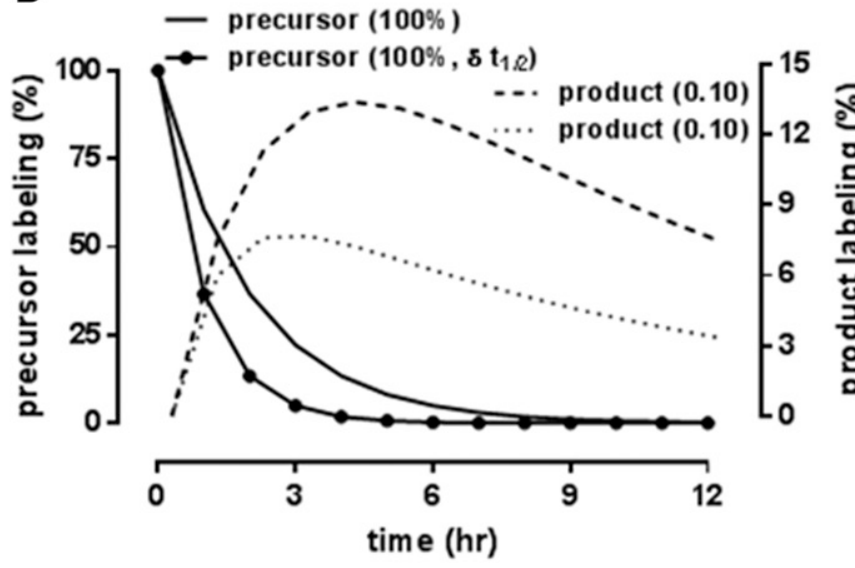

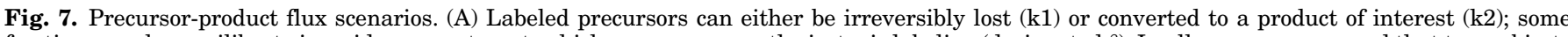

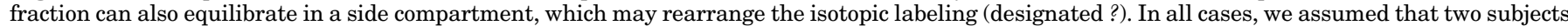

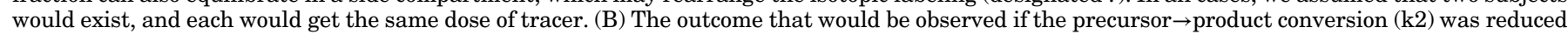

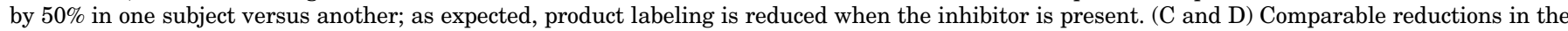

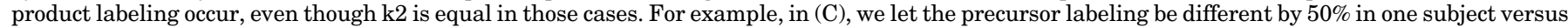

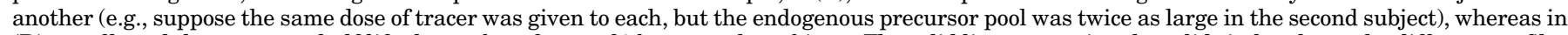

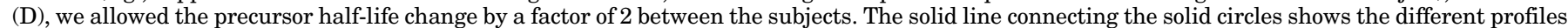
of precursor labeling $(\mathrm{C}$ and $\mathrm{D})$ in the respective subjects, and the dotted lines represent the corresponding product labeling. 

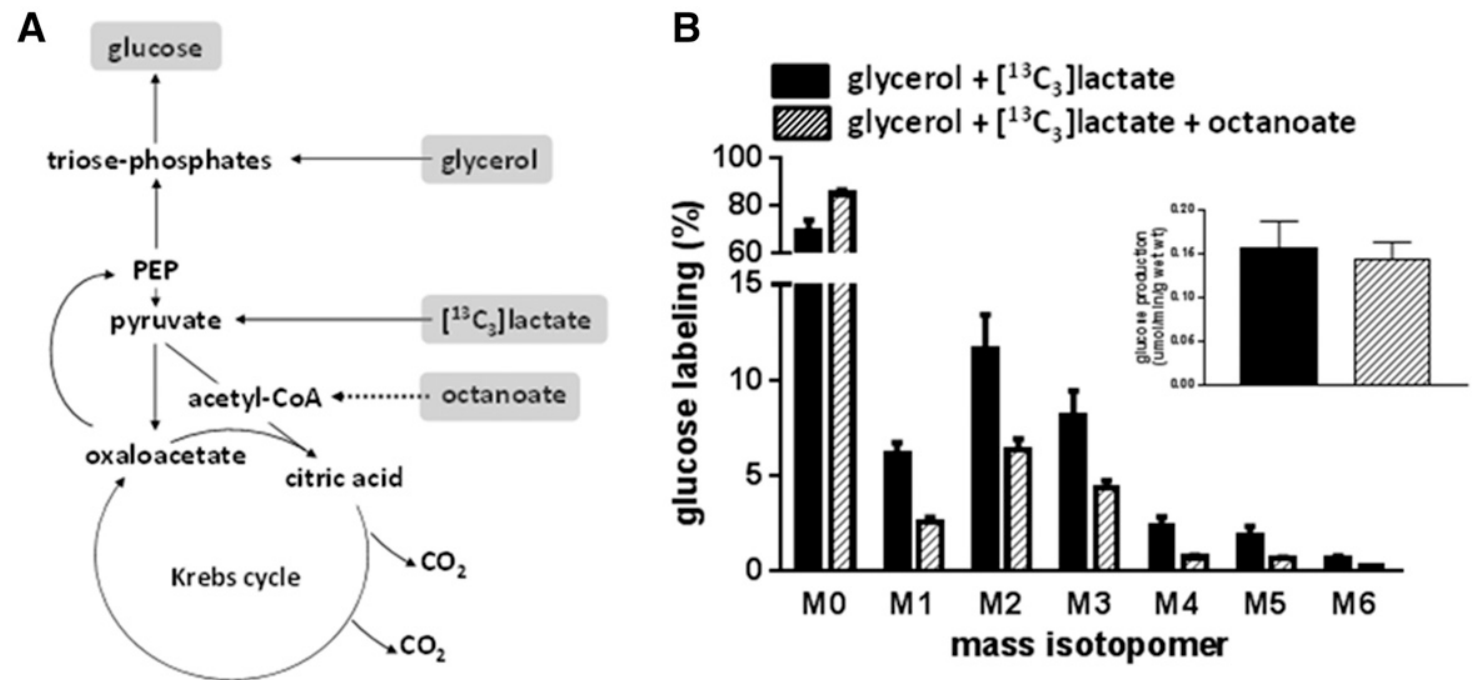

Fig. 8. Net flux versus isotopic dilution and exchange. The abbreviated scheme in (A) demonstrates key steps in the gluconeogenic pathway that are relevant to the entry of various substrates. Previous experiments measured the isotopic distribution of glucose when rat livers were perfused in an open circuit with $0.1 \mathrm{mM}$ glycerol and $1.0 \mathrm{mM}\left[{ }^{13} \mathrm{C}_{3}\right]$ lactate \pm octanoate (Previs et al., 1995). The spectra contained in (B) demonstrate marked "scrambling" of isotope labeling as the $\left[\mathrm{U}_{-}^{13} \mathrm{C}_{3}\right]$ lactate $(\mathrm{M}+3)$ precursor is converted to $\left[{ }^{13} \mathrm{C}\right]$ glucose. The addition of octanoate leads to a reduction in the enrichment of glucose. If one considers the abundance of $\left[{ }^{13} \mathrm{C}\right]$ to reflect the rate of glucose production, one would erroneously conclude that octanoate acts as an inhibitor of the pathway flux (the inset demonstrates that there was no change in glucose production). The differences in the $\left[{ }^{13} \mathrm{C}\right] l$ labeling reflect dilution of the tracer as the $\left[{ }^{13} \mathrm{C}_{3}\right]$ lactate precursor is converted to $\left[{ }^{13} \mathrm{C}\right]$ glucose. These data are reproduced from another report (Previs et al., 1995).

which is consistent with known biochemical schemes (Weinman et al., 1957; Krebs et al., 1966) and experimental data (Katz et al., 1993; Landau et al., 1998). In addition to the $\left[{ }^{13} \mathrm{C}\right]$ scrambling, if we consider only the abundance of $\left[{ }^{13} \mathrm{C}\right]-$ labeled glucose as a readout of pathway activity, we would conclude that octanoate is an inhibitor of glucose production. This is not true, glucose production is equal in the groups (Fig. 8, inset); the addition of octanoate actually adds more $\left[{ }^{12} \mathrm{C}\right]$ substrate, which therein dilutes the $\left[{ }^{13} \mathrm{C}\right]$ lactate as it undergoes conversion to glucose (Weinman et al., 1957). Since enzymes and pathways affect the simultaneous conversion of tracers and tracees, it is critical to measure enrichment, and one should generally avoid measuring the fate of the tracer alone (Landry et al., 2011).

\section{Summary and Final Conclusions}

It is hoped that readers will recognize that tracer kinetics add a new dimension in studies of pathway biology; measurements of metabolic flux can yield novel insight regarding studies of pharmacodynamic mechanisms (Fig. 1). We have reviewed examples that represent broad concepts in the field of tracer kinetics to outline first principles (Fig. 2 and 3); presumably, we have made the subject matter more conversational by minimizing the discussion of equations and emphasizing parallel problems. We recognize that some aspects of our review differ markedly from the literature, and we apologize to any authors who feel singled out in this report; there is no intention to discredit the efforts of any individual or group.

We believe stable isotope tracer methods can yield novel insight into questions surrounding biochemical flux and inform on the pathophysiology in disease states. Our theoretical model (Fig. 3), along with experimental measurements of water flux (Figs. 4 and 5), can be used to represent numerous scenarios, including pulse-chase designs and studies of different metabolic states. Of course, the scenario that we have used (e.g., a single compartment with a stable pool size) represents the simplest type of problem.

Since the concentration of an endpoint reflects the difference between the rates of synthesis and degradation, one can infer degradation rates by measuring the temporal change in pool size and the rate of synthesis (Fig. 6, period 2). Readers should appreciate the fact that tracers and tracees have the same fate. Since one can derive estimates of fractional turnover and flux rate from the labeling pulse phase of an experiment, it may not be necessary to measure dilution during the chase phase; perhaps our discussion can help to simplify experimental designs. Additionally, the subtle disconnect between the mathematical modeling that is applied to pharmacokinetics and tracer kinetics requires attention (Figs. 7 and 8). Metabolic flux can affect the downstream labeling in precursor-product relationships; therefore, a careful consideration of analytical requirements is needed. Attention to these matters can allow investigators to reliably estimate flux, even in cases where isotope exchange is present.

\section{Acknowledgments}

During the course of this work, N.A.D., S.P.W., Y.C., H.Z, D.G.M., T.P.R., D.G.J., D.M.E., D.E.K., and S.F.P. were or currently are employed by and/or own stock in Merck.

\section{Authorship Contributions}

Participated in the research design: Daurio, Wang, Chen, Zhou, Milot, Roddy, Johns, Milot, Erion, Kelley, Previs, Kasumov.

Conducted experiments: Daurio, Wang, Chen, Zhou, McLauren, Milot, Previs.

Performed data analyses: Daurio, Wang, Chen, Zhou, McLauren, Roddy, Johns, Milot, Previs, Kasumov.

Wrote or contributed to the writing of the manuscript: Daurio, Wang, Chen, Zhou, Milot, Roddy, Johns, Milot, Erion, Kelley, Previs, Kasumov. 


\section{References}

Arrowsmith J and Miller P (2013) Trial watch: phase II and phase III attrition rates 2011-2012. Nat Rev Drug Discov 12:569.

Bateman RJ, Munsell LY, Chen X, Holtzman DM, and Yarasheski KE (2007) Stable isotope labeling tandem mass spectrometry (SILT) to quantify protein production and clearance rates. J Am Soc Mass Spectrom 18:997-1006.

Bateman RJ, Munsell LY, Morris JC, Swarm R, Yarasheski KE, and Holtzman DM (2006) Human amyloid-beta synthesis and clearance rates as measured in cerebrospinal fluid in vivo. Nat Med 12:856-861.

Bederman IR, Dufner DA, Alexander JC, and Previs SF (2006) Novel application of the "doubly labeled" water method: measuring CO2 production and the tissuespecific dynamics of lipid and protein in vivo. Am J Physiol Endocrinol Metab 290: E1048-E1056.

Bederman IR, Foy S, Chandramouli V, Alexander JC, and Previs SF (2009) Triglyceride synthesis in epididymal adipose tissue: contribution of glucose and nonglucose carbon sources. J Biol Chem 284:6101-6108.

Berman M, Grundy SM, and Howard BV (1982) Lipoprotein Kinetics and Modeling, Academic Press, New York.

Brunengraber DZ, McCabe BJ, Kasumov T, Alexander JC, Chandramouli V, and Previs SF (2003) Influence of diet on the modeling of adipose tissue triglycerides during growth. Am J Physiol Endocrinol Metab 285:E917-E925.

Cascante M, Boros LG, Comin-Anduix B, de Atauri P, Centelles JJ, and Lee PW (2002) Metabolic control analysis in drug discovery and disease. Nat Biotechnol 20:243-249.

Chavez-Jauregui RN, Mattes RD, and Parks EJ (2010) Dynamics of fat absorption and effect of sham feeding on postprandial lipema. Gastroenterology 139:1538-1548.

Cleland WW (2005) The use of isotope effects to determine enzyme mechanisms. Arch Biochem Biophys 433:2-12.

Cline GW, Petersen KF, Krssak M, Shen J, Hundal RS, Trajanoski Z, Inzucchi S, Dresner A, Rothman DL, and Shulman GI (1999) Impaired glucose transport as a cause of decreased insulin-stimulated muscle glycogen synthesis in type 2 diabetes. $N$ Engl $J$ Med 341:240-246.

Cook D, Brown D, Alexander R, March R, Morgan P, Satterthwaite G, and Pangalos MN (2014) Lessons learned from the fate of AstraZeneca's drug pipeline: a fivedimensional framework. Nat Rev Drug Discov 13:419-431.

Cook JJ, Wildsmith KR, Gilberto DB, Holahan MA, Kinney GG, Mathers PD, Michener MS, Price EA, Shearman MS, Simon AJ, et al. (2010) Acute gammasecretase inhibition of nonhuman primate CNS shifts amyloid precursor protein (APP) metabolism from amyloid-beta production to alternative APP fragments without amyloid-beta rebound. J Neurosci 30:6743-6750.

Cuchel M, Schaefer EJ, Millar JS, Jones PJ, Dolnikowski GG, Vergani C, and Lichtenstein $\mathrm{AH}$ (1997) Lovastatin decreases de novo cholesterol synthesis and LDL Apo B-100 production rates in combined-hyperlipidemic males. Arterioscler Thromb Vasc Biol 17:1910-1917.

Decaris ML, Emson CL, Li K, Gatmaitan M, Luo F, Cattin J, Nakamura C, Holmes WE, Angel TE, Peters MG, et al. (2015) Turnover rates of hepatic collagen and circulating collagen-associated proteins in humans with chronic liver disease. PLoS One 10:e0123311.

Decaris ML, Li KW, Emson CL, Gatmaitan M, Liu S, Wang Y, Nyangau E, Colangelo M, Angel TE, Beysen C, et al. (2017) Identifying nonalcoholic fatty liver disease patients with active fibrosis by measuring extracellular matrix remodeling rates in tissue and blood. Hepatology 65:78-88.

Dobrowolska JA, Michener MS, Wu G, Patterson BW, Chott R, Ovod V, Pyatkivskyy Y, Wildsmith KR, Kasten T, Mathers P, et al. (2014) CNS amyloid- $\beta$, soluble APP- $\alpha$ and $-\beta$ kinetics during BACE inhibition. $J$ Neurosci 34:8336-8346.

Donnelly KL, Smith CI, Schwarzenberg SJ, Jessurun J, Boldt MD, and Parks EJ (2005) Sources of fatty acids stored in liver and secreted via lipoproteins in patients with nonalcoholic fatty liver disease. J Clin Invest 115:1343-1351.

Edland SD and Galasko DR (2011) Fractional synthesis and clearance rates for amyloid $\beta$. Nat Med 17:1178-1179, author reply 1179-1180.

Ekberg K, Landau BR, Wajngot A, Chandramouli V, Efendic S, Brunengraber H, and Wahren J (1999) Contributions by kidney and liver to glucose production in the postabsorptive state and after $60 \mathrm{~h}$ of fasting. Diabetes 48:292-298.

Elbert DL, Patterson BW, and Bateman RJ (2015) Analysis of a compartmental model of amyloid beta production, irreversible loss and exchange in humans. Math Biosci 261:48-61.

Fell D (1997) Understanding the Control of Metabolism, Portland Press, London.

Fielding CJ (1976) Lipoprotein lipase: evidence for high- and low-affinity enzyme sites. Biochemistry 15:879-884.

Foster DM, Barrett PH, Toffolo G, Beltz WF, and Cobelli C (1993) Estimating the fractional synthetic rate of plasma apolipoproteins and lipids from stable isotope data. J Lipid Res 34:2193-2205.

Gabrielsson J and Weiner D (2000) Pharmacokinetic and Pharmacodynamic Data Analysis: Concepts and Applications, Swedish Pharmaceutical Press, Stockholm.

Grundy SM, Mok HY, Zech L, Steinberg D, and Berman M (1979) Transport of very low density lipoprotein triglycerides in varying degrees of obesity and hypertriglyceridemia. J Clin Invest 63:1274-1283.

Harding SV, Bateman KP, Kennedy BP, Rideout TC, and Jones PJ (2015) Desaturation index versus isotopically measured de novo lipogenesis as an indicator of acute systemic lipogenesis. BMC Res Notes 8:49-56.

Heath DF and Barton RN (1973) The design of experiments using isotopes for the determination of the rates of disposal of blood-borne substrates in vivo with special reference to glucose, ketone bodies, free fatty acids and proteins. Biochem $J \mathbf{1 3 6}$ 503-518.

Holm L, O’Rourke B, Ebenstein D, Toth MJ, Bechshoeft R, Holstein-Rathlou NH, Kjaer M, and Matthews DE (2013) Determination of steady-state protein breakdown rate in vivo by the disappearance of protein-bound tracer-labeled amino acids: a method applicable in humans. Am J Physiol Endocrinol Metab 304:E895-E907.

Hundal RS, Krssak M, Dufour S, Laurent D, Lebon V, Chandramouli V, Inzucchi SE Schumann WC, Petersen KF, Landau BR, et al. (2000) Mechanism by which metformin reduces glucose production in type 2 diabetes. Diabetes 49:2063-2069.
Jensen KK, Previs SF, Zhu L, Herath K, Wang SP, Bhat G, Hu G, Miller PL, McLaren DG, Shin MK, Vogt TF, Wang L, Wong KK, Roddy TP, Johns DG, and Hubbard BK (2012) Demonstration of diet-induced decoupling of fatty acid and cholesterol synthesis by combining gene expression array and $2 \mathrm{H} 2 \mathrm{O}$ quantification. Am J Physiol Endocrinol Metab 302:E209-E217.

Jin ES, Sherry AD, and Malloy CR (2013) Metabolism of glycerol, glucose, and lactate in the citric acid cycle prior to incorporation into hepatic acylglycerols. J Biol Chem 288:14488-14496.

Kasturi S, Bederman IR, Christopher B, Previs SF, and Ismail-Beigi F (2007) Exposure to azide markedly decreases the abundance of mRNAs encoding cholesterol synthetic enzymes and inhibits cholesterol synthesis. $J$ Cell Biochem 100:1034-1044.

Katz J (1992) On the determination of turnover in vivo with tracers. Am J Physiol 263:E417-E424.

Katz J, Wals P, and Lee WN (1993) Isotopomer studies of gluconeogenesis and the Krebs cycle with 13C-labeled lactate. J Biol Chem 268:25509-25521.

Krebs HA, Hems R, Weidemann MJ, and Speake RN (1966) The fate of isotopic carbon in kidney cortex synthesizing glucose from lactate. Biochem $J$ 101:242-249.

Landau BR and Wahren J (1992) Nonproductive exchanges: the use of isotopes gone astray. Metabolism 41:457-459.

Landau BR, Wahren J, Ekberg K, Previs SF, Yang DW, and Brunengraber H (1998) Limitations in estimating gluconeogenesis and Cori cycling from mass isotopomer distributions using [U-C-13(6)]glucose. Am J Physiol Endocrinol Metab 274: E954-E961.

Landry F, Chan CC, Huang Z, Leclair G, Li CS, Oballa R, Zhang L, and Bateman K (2011) Plasma-based approach to measure target engagement for liver-targeting stearoyl-CoA desaturase 1 inhibitors. J Lipid Res 52:1494-1499.

Lee WN, Bassilian S, Ajie HO, Schoeller DA, Edmond J, Bergner EA, and Byerley LO (1994) In vivo measurement of fatty acids and cholesterol synthesis using D2O and mass isotopomer analysis. Am J Physiol 266:E699-E708.

Lichtenstein AH, Cohn JS, Hachey DL, Millar JS, Ordovas JM, and Schaefer EJ (1990) Comparison of deuterated leucine, valine, and lysine in the measurement of human apolipoprotein A-I and B-100 kinetics. J Lipid Res 31:1693-1701.

London IM (1949) The use of stable isotopes in biological and medical research. J Clin Invest 28:1255-1270.

Mawuenyega KG, Sigurdson W, Ovod V, Munsell L, Kasten T, Morris JC, Yarashesk $\mathrm{KE}$, and Bateman RJ (2010) Decreased clearance of CNS beta-amyloid in Alzheimer's disease. Science 330:1774.

McLaren DG, Cardasis HL, Stout SJ, Wang SP, Mendoza V, Castro-Perez JM, Miller PL, Murphy BA, Cumiskey AM, Cleary MA, et al. (2013) Use of [13C18] oleic acid and mass isotopomer distribution analysis to study synthesis of plasma triglycerides in vivo: analytical and experimental considerations. Anal Chem 85:6287-6294.

McLaren DG, Previs SF, Phair RD, Stout SJ, Xie D, Chen Y, Salituro GM, Xu SS, Castro-Perez JM, Opiteck GJ, et al. (2016) Evaluation of CETP activity in vivo under non-steady-state conditions: influence of anacetrapib on HDL-TG flux. J Lipid Res 57:398-409.

Millar JS, Reyes-Soffer G, Jumes P, Dunbar RL, deGoma EM, Baer AL, Karmally W, Donovan DS, Rafeek H, Pollan L, et al. (2015) Anacetrapib lowers LDL by increasing ApoB clearance in mildly hypercholesterolemic subjects. $J$ Clin Invest 125:2510-2522

Mittendorfer B, Sidossis LS, Walser E, Chinkes DL, and Wolfe RR (1998) Regional acetate kinetics and oxidation in human volunteers. Am J Physiol 274:E978-E983.

Muramatsu K, Sato T, and Ashida K (1963) Dietary protein level and the turnover rate of tissue proteins in rats. $J$ Nutr 81:427-433.

Newsholme EA (1978) Substrate cycles: their metabolic, energetic and thermic consequences in man. Biochem Soc Symp 43:183-205.

Parhofer KG, Hugh P, Barrett R, Bier DM, and Schonfeld G (1991) Determination of kinetic parameters of apolipoprotein $\mathrm{B}$ metabolism using amino acids labeled with stable isotopes. J Lipid Res 32:1311-1323.

Park JO, Rubin SA, Xu YF, Amador-Noguez D, Fan J, Shlomi T, and Rabinowitz JD (2016) Metabolite concentrations, fluxes and free energies imply efficient enzyme usage. Nat Chem Biol 12:482-489.

Petersen KF, Krssak M, Inzucchi S, Cline GW, Dufour S, and Shulman GI (2000) Mechanism of troglitazone action in type 2 diabetes. Diabetes 49:827-831.

Plenge RM, Scolnick EM, and Altshuler D (2013) Validating therapeutic targets through human genetics. Nat Rev Drug Discov 12:581-594.

Poole B (1971) The kinetics of disappearance of labeled leucine from the free leucine pool of rat liver and its effect on the apparent turnover of catalase and other hepatic proteins. J Biol Chem 246:6587-6591

Previs SF, Fernandez CA, Yang DW, Soloviev MV, David F, and Brunengraber H (1995) Limitations of the Mass Isotopomer Distribution Analysis of Glucose to Study Gluconeogenesis - Substrate Cycling Between Glycerol and Triose Phosphates in Liver. Journal of Biological Chemistry 270:19806-19815.

Previs SF, Fatica R, Chandramouli V, Alexander JC, Brunengraber H, and Landau BR (2004) Quantifying rates of protein synthesis in humans by use of $2 \mathrm{H} 2 \mathrm{O}$ : application to patients with end-stage renal disease. Am J Physiol Endocrinol Metab 286:E665-E672

Previs SF and Kelley DE (2015) Tracer-based assessments of hepatic anaplerotic and TCA cycle flux: practicality, stoichiometry, and hidden assumptions. Am J Physiol Endocrinol Metab 309:E727-E735.

Previs SF, McLaren DG, Wang SP, Stout SJ, Zhou H, Herath K, Shah V, Miller PL, Wilsie L, Castro-Perez J, et al. (2014) New methodologies for studying lipid synthesis and turnover: looking backwards to enable moving forwards. Biochim Biophys Acta 1842:402-413.

Ramakrishnan R (2006) Studying apolipoprotein turnover with stable isotope tracers: correct analysis is by modeling enrichments. J Lipid Res 47:2738-2753.

Ratheiser KM, Pesola GR, Campbell RG, and Matthews DE (1999) Epinephrine transiently increases amino acid disappearance to lower amino acid levels in humans. JPEN J Parenter Enteral Nutr 23:279-287. 
Reiner JM (1953a) The study of metabolic turnover rates by means of isotopic tracers. I. Fundamental relations. Arch Biochem Biophys 46:53-79.

Reiner JM (1953b) The study of metabolic turnover rates by means of isotopic tracers. II. Turnover in a simple reaction system. Arch Biochem Biophys 46: 80-99.

Reyes-Soffer G, Pavlyha M, Ngai C, Thomas T, Holleran S, Ramakrishnan R, Karmally W, Nandakumar R, Fontanez N, Obunike J, et al. (2017) Effects of PCSK9 Inhibition With Alirocumab on lipoprotein metabolism in healthy humans. Circulation 135:352-362.

Robertson JS (1957) Theory and use of tracers in determining transfer rates in biological systems. Physiol Rev 37:133-154.

Rowland M and Tozer TN (2011) Clinical Pharmacokinetics and Pharmacodynamics: Concepts and Applications. Wolters Kluwer Lippincott, Philadelphia.

Shah V, Herath K, Previs SF, Hubbard BK, and Roddy TP (2010) Headspace analyses of acetone: a rapid method for measuring the $2 \mathrm{H}$-labeling of water. Anal Biochem 404:235-237.

Shipley RA and Clark RE (1972) Tracer Methods for In Vivo Kinetics: Theory and Applications, Academic Press, New York.

Solomon AK (1949) Equations for tracer experiments. J Clin Invest 28:1297-1307.

Steele R (1971) Tracer probes in steady-state systems. Charles C Thomas, Springfield, Illinois.

Stiede K, Miao W, Blanchette HS, Beysen C, Harriman G, Harwood, JrHJ, Kelley H, Kapeller R, Schmalbach T, and Westlin WF (2017) Acetyl-coenzyme A carboxylase inhibition reduces de novo lipogenesis in overweight male subjects: a randomized, double-blind, crossover study. Hepatology 66:324-334.

Sunny NE, Parks EJ, Browning JD, and Burgess SC (2011) Excessive hepatic mitochondrial TCA cycle and gluconeogenesis in humans with nonalcoholic fatty liver disease. Cell Metab 14:804-810.

Turner SM and Hellerstein MK (2005) Emerging applications of kinetic biomarkers in preclinical and clinical drug development. Curr Opin Drug Discov Devel 8:115-126.

Turner SM, Roy S, Sul HS, Neese RA, Murphy EJ, Samandi W, Roohk DJ, and Hellerstein MK (2007) Dissociation between adipose tissue fluxes and lipogenic gene expression in ob/ob mice. Am J Physiol Endocrinol Metab 292:E1101-E1109.
Vaitheesvaran B, Chueh FY, Xu J, Trujillo C, Saad MF, Lee WN, McGuinness OP, and Kurland IJ (2010) Advantages of dynamic "closed loop" stable isotope flux phenotyping over static "open loop" clamps in detecting silent genetic and dietary phenotypes. Metabolomics 6:180-190.

van Dijk TH, Laskewitz AJ, Grefhorst A, Boer TS, Bloks VW, Kuipers F, Groen AK and Reijngoud DJ (2013) A novel approach to monitor glucose metabolism using stable isotopically labelled glucose in longitudinal studies in mice. Lab Anim 47:79-88.

Wahrheit J, Niklas J, and Heinzle E (2014) Metabolic control at the cytosolmitochondria interface in different growth phases of CHO cells. Metab Eng 23:9-21.

Wang SP, Zhou D, Yao Z, Satapati S, Chen Y, Daurio NA, Petrov A, Shen X, Metzger $\mathrm{D}$, Yin W, et al. (2016) Quantifying rates of glucose production in vivo following an intraperitoneal tracer bolus. Am J Physiol Endocrinol Metab 311:E911-E921.

Waterlow JC (2006) Protein Turnover, CABI, Oxfordshire, UK.

Weinman EO, Strisower EH, and Chaikoff IL (1957) Conversion of fatty acids to carbohydrate; application of isotopes to this problem and role of the Krebs cycle as a synthetic pathway. Physiol Rev 37:252-272.

Wolfe RR and Chinkes DL (2005) Isotope Tracers in Metabolic Research: Principles and Practice of Kinetic Analyses, Wiley-Liss, Hoboken, NJ.

Zhou H, Wang SP, Herath K, Kasumov T, Sadygov RG, Previs SF, and Kelley DE (2015) Tracer-based estimates of protein flux in cases of incomplete product renewal: evidence and implications of heterogeneity in collagen turnover. Am J Physiol Endocrinol Metab 309:E115-E121.

Zierler KL (1961) Theory of the use of arteriovenous concentration differences for measuring metabolism in steady and non-steady states. $J$ Clin Invest 40 : $2111-2125$

Zilversmit DB (1960) The design and analysis of isotope experiments. Am J Med 29: 832-848.

Address correspondence to: Dr. Stephen F. Previs, Merck \& Co., Inc., Kenilworth, NJ 07033. E-mail: stephen_previs@merck.com 